\title{
Infrared visualisation of flow within inclined louvered fins
}

\author{
by C. T'Joen*, A. Willockx* and M. De Paepe*
}

*Department of Flow, Heat and Combustion Mechanics, Ghent University-UGent, Gent, Belgium

\begin{abstract}
Modern compact fin-and-tube heat exchangers use very complex fin designs on the air side. Common designs include louvered fins, offset strip fins... These corrugated fin types increase the heat transfer rate when compared to plate fins, but also cause a large increase in pressure drop. Air conditioning manufacturers seek out new fin types to further enhance the performance of their evaporators/condensers and thus increase overall unit efficiency. The 'inclined louvered fin' (Fig.1) is a hybrid design between a standard louvered fins and an offset strip fin. It is aimed at improved performance (less pressure drop for a given heat transfer rate) at low Reynolds numbers. To investigate the thermo-hydraulic characteristics a test rig (Fig. 2) was built to test a scaled model $(1: 20)$. The test rig is an open air wind tunnel. Air is blown through the test section (7) by a fan (3), driven by a frequency controlled motor (1-2). To provide a uniform velocity distribution the flow is sent through a settling chamber with honeycomb (4-5) and a settling channel (6). The air mass flow rate is measured using an orifice calibrated according to the ISO 5167 norm. The scaling of the test section allows for local measurement of surface temperatures and air velocities, thus providing data for validation of numerical computations.
\end{abstract}

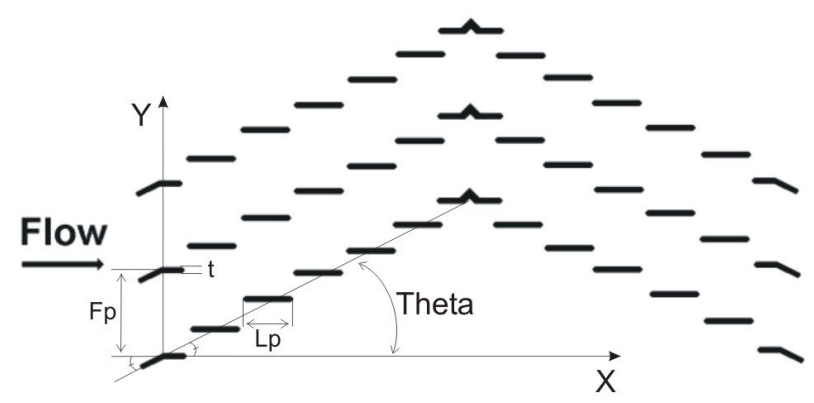

Fig. 1. Inclined louvered fin: parameters.

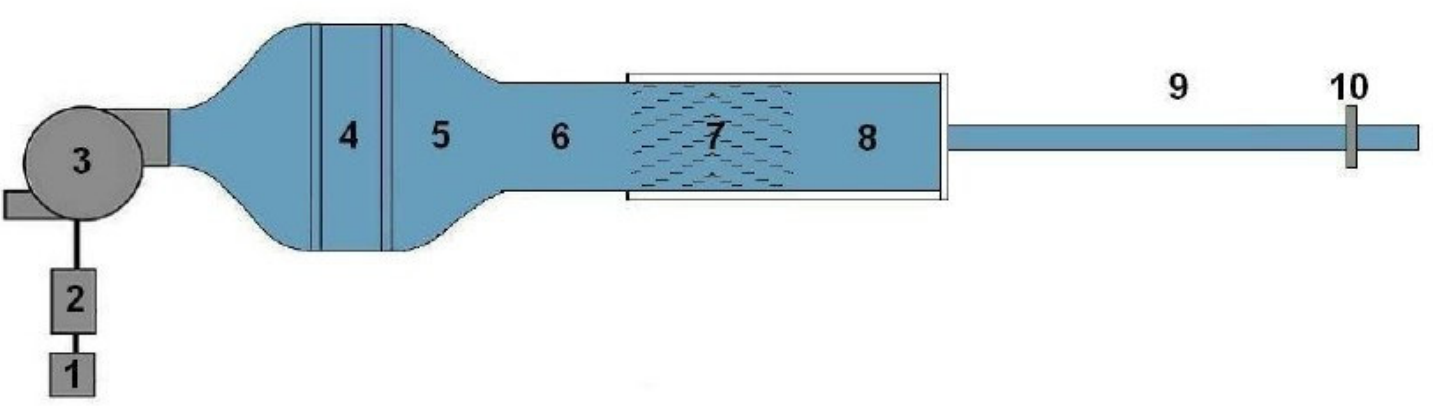

Fig. 2. Test rig.

To study the flow within the fin array a thin paper sheet (emissivity 0.94) was placed at the center of the wind tunnel (Fig. 3), and several IR windows (using mica foil, 80\% IR-transparent) were made on one side of the channel. By using an infrared camera local images of the air temperature profile can be recorded without disturbing the flow. IR-images have been recorded for various geometric configurations (with different fin pitch and fin angle), at various Reynolds numbers (ranging from 800 to 2000) and for a range of heat fluxes. Figure 4 presents four examples for a single geometry compared to numerical simulations. It is found that this technique provides a qualitative image of the flow pattern through the fin array and shows several distinct flow features: the long cold wake which flows through the array, local hot wakes just downstream of louver (e.g. case 1), hot recirculation zone behind the turnaround section... The images can also be used to distinguish the type of flow: the IR-images of case 1 and 2 clearly show a steady laminar flow, while case 3 and 4 present more erratic patterns, as the flow has become unsteady (CFD simulation) and vortices are being shed by the louvers. This gives rise to a more 'spotted' temperature profile (case 4). In order to have a good resolution, there must be sufficient temperature difference between the inlet and outlet. For case 3 the temperature difference is too small but all other cases. 
http://dx.doi.org/10.21611/qirt.2008.07_09_11

QIRT2008

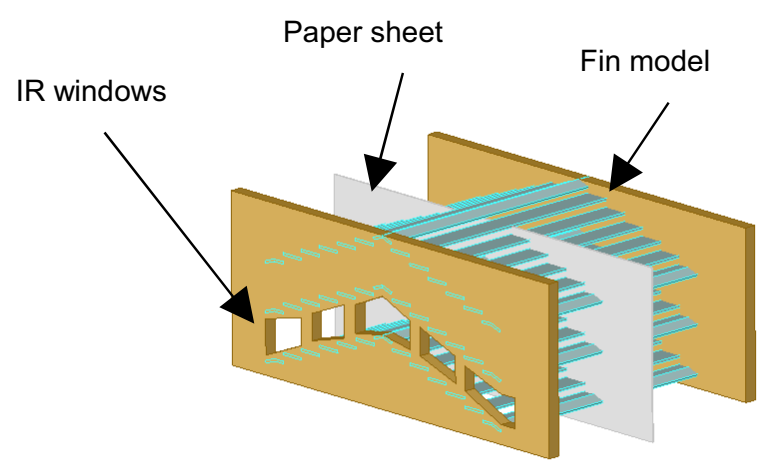

Fig. 3. Experimental setup.

Case 1: Reynolds number: 800 and heat flux: $80 \mathrm{~W} / \mathrm{m}^{2}$

IR-visualisation
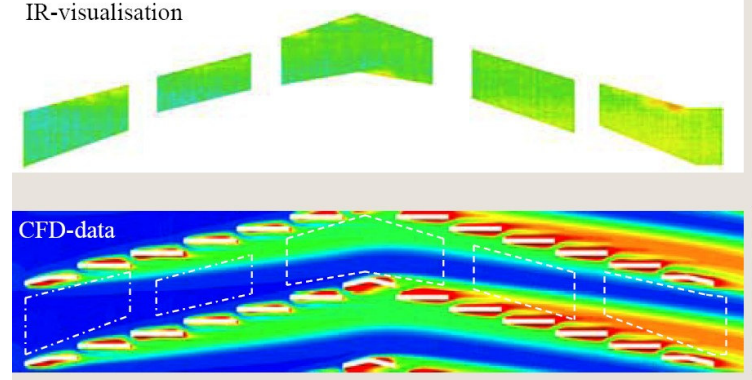

Case 3: Reynolds number: 2000 and heat flux: $80 \mathrm{~W} / \mathrm{m}^{2}$ IR-visualisation
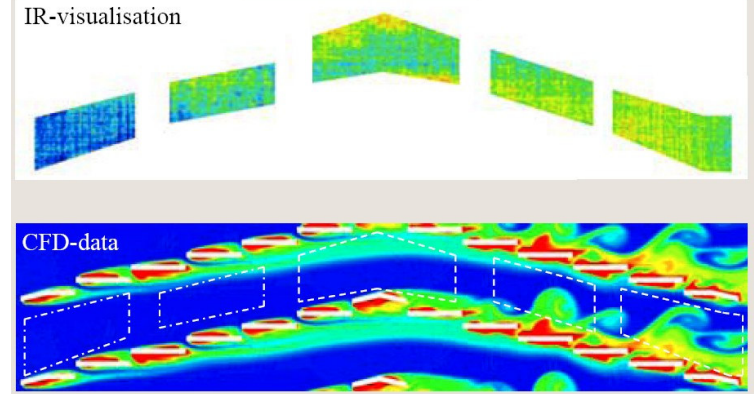

Case 2: Reynolds number: 800 and heat flux: $180 \mathrm{~W} / \mathrm{m}^{2}$

IR-visualisation
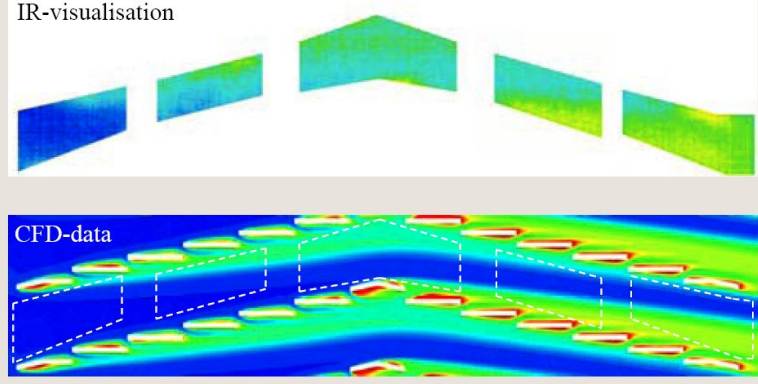

Case 4: Reynolds number: 2000 and heat flux: $180 \mathrm{~W} / \mathrm{m}^{2}$ IR-visualisation
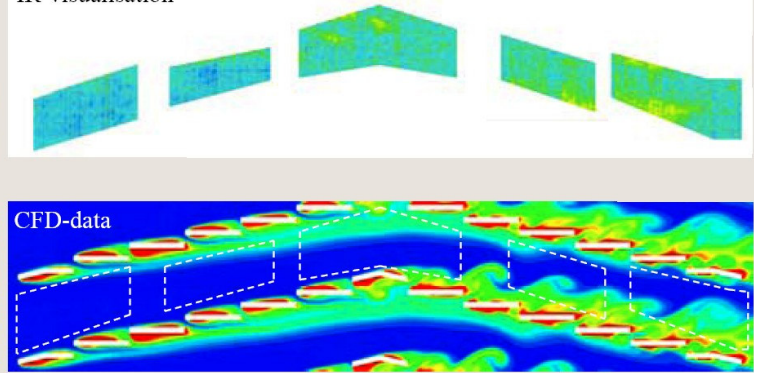

Fig. 4. Measurements compared to CFD simulations. 